\title{
PREDICTING VOLUNTEERS’ INTENTION TO RETURN: AN EXAMINATION OF BRAND PERSONALITY, PRESTIGE, AND IDENTIFICATION OF SPORTING EVENTS
}

\author{
HYEJIN BANG,* SOONHWAN LEE,† AND KAMILLA SWART $\ddagger$ \\ *Department of Leadership and Professional Studies, Florida International University, Miami, FL, USA \\ †Department of Physical Education, Indiana University-Purdue University Indianapolis, \\ Indianapolis, IN, USA \\ ¥Cape Peninsula University of Technology, Cape Town, South Africa
}

\begin{abstract}
The purpose of this study was to examine the relationship among four variables: brand personality traits, prestige of a sporting event, brand identification, and individuals' intention to return to volunteer for future sporting events. Five personality traits were included in the study: sincerity, excitement, competence, sophistication, and ruggedness. A proposed conceptual model was developed and tested with a sample of volunteers at the 2010 FIFA World Cup in South Africa. Two hundred twenty-four individuals participated in a self-administered questionnaire during the event. Results from structural equation model analysis showed that three brand personality dimensions-sincerity, competence, and sophistication - were associated with individuals' prestige of the sporting event. Furthermore, event prestige positively influenced brand identification, which had a positive impact on volunteers' intention to return for volunteering.
\end{abstract}

Key words: Brand personality; Prestige; Brand identification; Intention to return; Sporting events

\section{Introduction}

Recruiting and retaining volunteers are essential parts of managing most sporting events, especially large-scale sporting events such as the Olympic Games and the FIFA World Cup. For example, more than 25,000 volunteers participated in the Vancouver 2010 Winter Olympics to help the athletes, visitors, and spectators and served in over 32 different functional areas (Vancouver 2010, 2010). The contribution and wider impact of volunteers are particularly significant, both to the event operations and within the host community (Baum \& Lockstone, 2007). Research has focused on what motivates and retains individuals to volunteer. If event organizers are cognizant of 
various volunteer motivations and effectively manage volunteer experiences, such effort would result in retaining a strong volunteer base in the community for future sporting events (Farrell, Johnston, \& Twynam, 1998). However, the importance of the characteristics of a branded sporting event in individuals' decision-making process toward volunteering at the sporting event has not been widely acknowledged. Researchers in numerous sport marketing studies have suggested that the attraction to a sport product (e.g., a sport team) is influenced by the product's brand personality, which supports the idea that a brand personality often increases the consumer's connection with the brand (J. L. Aaker, 1997). In this manner, certain characteristics of the FIFA World Cup would have probably attracted a large number of individuals. Volunteering at such a history-making event or world class sporting event could bring special enjoyment and experiences to them, which are different from their feeling at other sporting events. Numerous motivational researchers argue that individuals' altruistic and egoistic motivations play an important role in volunteering at a sporting event. However, in addition to volunteer motivation, a strong brand personality of a sporting event can bring image enhancement and lead to individuals' increased willingness to volunteer at or continue volunteering for the event (P. L. Chang \& Chieng, 2006; Kressman et al., 2006). Therefore, this study sought to examine the relationship among four variables: brand personality traits, prestige of a sporting event, brand identification, and individuals' intention to return to volunteer for future sporting events.

\section{Theoretical Background and Hypotheses}

\section{Brand Personality}

Brand is defined as a name, term, design, symbol, or any other feature to identify goods or services of one seller as distinct from those sellers of similar goods or services (American Marketing Association, 2008). In the sport industry, sporting events (e.g., the NFL's Super Bowl, the NCAA's March Madness, the Summer Olympics, and the FIFA World Cup) are considered brands that can be distinguished from other similar events because the brand valuation of such events is compiled by television rights fees, sponsorship revenue, ticket receipts, and licensing revenue (Schwartz, 2007). For example, for Major League Baseball's World Series, the television rights fee for the championship games is not broken out from the regular season or other postseason games (Schwartz, 2007). Previous consumer research has suggested that consumers form strong attachments to brands, which reflects their commitment to the brand and their willingness to make sacrifices to maintain the relationship (McAlexander, Schouten, \& Koenig, 2002). As such, it is commonly accepted that a strong, recognizable brand provides a company with numerous benefits that establish the company's identity in the market place, creating a competitive advantage to the company over its rivals (D. A. Aaker, 1991).

Brand has a set of personality traits, which is the way companies present their products to the consumer. J. L. Aaker (1997) defines brand personality as "the set of human characteristics associated with a brand” (p. 347). Brand personality can be instrumental in helping consumers express different aspects of themselves (Escalas \& Bettman, 2005) as they use brands to build and sustain their identity and to experience emotional gratification (J. L. Aaker, 1996). The concept of brand personality derives from the theory of symbolism (Ekinci \& Hosany, 2006). From the perspective of the theory of symbolism, consumers tend to view that the brand personality of their preferred product is congruent with their self-image (K. S. Chang, Park, \& Choi, 2001). The congruence between brand personality and self-image increases positive attitude of consumers who emphasize symbolic values, leading to enhanced consumer satisfaction and consumerbrand relationship (Ekinci \& Hosany, 2006). In line with this view, Carlson, Donavan, and Cumiskey (2009) applied brand personality concept to examine the relationships between the brand personality of a sports team and the related consumer outcomes of identification and retail spending. They found that brand personality directly and indirectly influenced identification with the team, and the team cognitive identification had a significant impact on games watched and retail spending. Therefore, we suggest that, similar to sport team brands, branded sporting events are valuable on the subject of symbolic values and personality traits given that they contain a number of tangible and intangible attributes 
regarding the event characteristics (e.g., size, professional status, history, venue, and promotional appearance) and individual factors (e.g., meanings associated with the event, strength of meanings, and history with the event) (Gwinner, 1997).

J. L. Aaker (1997) identified five dimensions of brand personality: sincerity, excitement, competence, sophistication, and ruggedness, each with multiple facets. Sincerity includes facets of being down-to-earth, honest, and wholesome; Dallas Cowboys, the once titled “America's Team” (Carlson et al., 2009), have this dimension in their brand personality. Excitement includes such facets as being daring, spirited, imaginative, and up-to-date, which characterize the FIFA World Cup. Competence reflects such facets as being reliable, intelligent, and successful; many would agree ESPN has this dimension. Sophistication applies to brands, such as PGA championship, that are viewed as upper class and charming. Ruggedness applies to events that are defined as outdoorsy and tough, such as the NFL's Oakland Raiders (Carlson et al., 2009). J. L. Aaker (1997) noted that a clearly defined brand personality helps make the brand distinct from competitors and helps individuals build a relationship with that brand. A well-branded sporting event includes certain traits to seize stakeholders' attention and helps the stakeholder to choose that sporting event over other related events.

The five dimensions of J. L. Aaker's (1997) brand personality scale have been replicated and extended across cultures and various settings. For example, J. L. Aaker, Benet-Martinez, and Garolera (2001) examined the brand personality constructs of commercial brands across three cultures: Japanese, Spanish, and American. They found that some of brand personality dimensions (i.e., sincerity, excitement, and sophistication) share similar meaning for all three cultures. However, some dimensions differed from those in J. L. Aaker's (1997) study in the US. A new dimension of peacefulness emerged in both Japanese and Spanish cultures; a new dimension of passion was specific to Spanish culture, while ruggedness represented US-specific brand personality dimensions. Unlike previous research focusing on brand personality of consumer goods, Carlson et al. (2009) investigated consumer-brand relationships in a sport setting using J. L. Aaker's (1997) brand personality scale. They argued because J. L. Aaker's
(1997) brand personality dimensions were initially developed to apply to traditional, tangible brands, their use for intangible quasibrands such as sport teams may be less appropriate. Their study thus used the facets of each dimension, including wholesome, imaginative, successful, charming, and tough, that were more applicable in the sport context. This study provides further evidence that brand personality may differ depending on the culture and the settings.

We believe that J. L. Aaker's (1997) brand personality scale can be extended to the sporting event context to gauge personality traits that individuals perceive when they choose a sporting event to volunteer. Accordingly, this study proposes that individuals create attachments to a branded sporting event with a certain personality; these attachments predict their willingness to continue to provide their time and effort for the sporting event as volunteers. Given that individuals' self-expressed desire to identify with a branded sporting event may be one of the essential attributes within the volunteer contribution process, this study examined a path model including two components of brand prestige and brand identification. These components may affect the relationship between sporting event brand personality and volunteers' intention to return.

\section{Brand Identification}

Brand identification is defined as the extent to which the consumer views one's own self-image as overlapping with the brand's image (Bagozzi \& Dholakia, 2006). Many studies have suggested that brand personality is strongly associated with brand identification. Brand identification is based on social identity theory (Tajfel \& Turner, 1979), which indicates that individuals often derive their self-concepts from social categories such as a demographic grouping, employment affiliation, or team membership (Carlson et al., 2009). Individuals may have ideal images of themselves in relation to the brand; these ideal images allow the individuals to express themselves, which is called ideal selfcongruity (Sirgy, Grewal, \& Mangleburg, 2000).

According to Sirgy (1982), self-congruity consists of at least two motives: self-consistency and self-esteem. The self-consistency motive reflects the need to act and behave in accordance with one's self-concept (Sirgy, 1982). Therefore, individuals 
who perceive the image of a sporting event to be consistent with their actual self-concept tend to feel motivated to volunteer for the sporting event. For example, the FIFA World Cup brings the joy of victory and the agony of defeat through exciting and unpredictable games, which would relate to the excitement brand personality dimension. This brand personality trait of the FIFA World Cup might lead individuals, who identify themselves as joyful and exciting, to be more committed to the World Cup event by watching its games or being part of the event as volunteers. The other motive of self-congruity, self-esteem refers to the proximity of the actual and the ideal self-concept (Rosenberg, 1979). The self-esteem motive is closely related to the need for social approval, which highlights one's ideal social self-image (Sirgy, 1986). Given that brands function as social symbols that contain a shared meaning, individual consumption behaviors attached to brands add considerably to the preservation and enhancement of individuals' self-concepts (Grubb \& Grathwohl, 1967).

The concept of self-congruity is closely associated with volunteers' motivational needs. Bang, Alexandris, and Ross (2009) identified seven dimensions of volunteer motivations at large-scale sporting events: expression of values, patriotism, interpersonal contacts, personal growth, career orientation, extrinsic rewards, and love of sport. These dimensions were also included in the volunteer motivations scale for international sporting events (VMS-ISE). Personal growth is one of the seven motivational dimensions reflecting that individuals are likely to increase their own feelings of self-worth and self-esteem through volunteer experiences at sporting events. In this respect, the prestige value of a sporting event seems to function as a catalyst to move individuals toward fulfilling their motivation and to express their social selfimage. According to Grubb and Grathwohl (1967), an individual often desires symbolic benefits of brands that include extrinsic values (e.g., prestige) and intrinsic values (e.g., self-expression). For example, individuals can use the prestige value of a brand to express their prestige, wealth, and status in their social surrounding (Deeter-Schmelz, Moore, \& Goeble, 2000). Considering individuals' desired symbolic benefits to be important factors in the mechanism that builds brand identification, this study posited that prestige of a brand (i.e., sporting event) has a mediator function that can better explain the relation between the antecedents (i.e., brand personality) and the results (i.e., brand identification) (Baron \& Kenny, 1986).

\section{Mediating Role of Prestige in the Relationship Between Brand Personality and Brand Identification}

Brand prestige represents a relatively high status of a product and/or service that is associated with a brand (Steenkamp, Batra, \& Alden, 2003). The key criterion that is used to determine the brand prestige is whether the brand has an inherent, unique know-how concerning either a specific attribute or the overall quality and performance of the brand product (Dubois \& Czellar, 2002). Dubois and Czellar (2002) distinguish between prestige and luxury: prestige has roots in a unique, exceptional accomplishment inherent to the brand, but luxury is related to comfort, beauty, and refinement, which represents hedonic benefits. For example, in service categories people accord prestige to brands based on the perceived exceptional accomplishment of the brand, so an educational institution is judged by the quality of teaching and research of faculty members (Dubois \& Czellar, 2002).

Carlson et al. (2009) emphasized that as a brand develops a more complex personality, the brand becomes more prestigious. In the light of Sirgy's (1982) self-congruity concept, once individuals possess brand associations (e.g., user characteristics, personality traits, reference groups, and personal experiences), they must possess a representation of their self-concept (e.g., the actual self, ideal self, or future self) including characteristics and traits that can be aligned with those possessed by brands (Chaplin \& John, 2005). Brand personality traits are more contextually specific than general group characteristics (Carlson et al., 2009) to accord with one's ideal self-concept. Carlson et al.'s (2009) study examining consumer-brand relationships in sport found that wholesomeness (i.e., sincerity) and success (i.e., competence) of brand personality contribute to team prestige, indicating that fans attribute proven success and a wholesome image with a prestigious sporting team. Therefore, we anticipated that volunteers' perceptions that a 
sporting event is sincere, exciting, competent, sophisticated, and/or rugged would build the exclusivity, respect, and status of the event (i.e., prestige), thereby engaging in a comparison process to determine whether the perceived brand prestige is congruent with their actual or desired self-concept (Chaplin \& John, 2005).

In the same vein, Belk (1991) noted that consumers express their own identity by connecting with prestigious brands. Individuals' perception of prestige of an organization or brand develops a sense of oneness with or belongingness to the organization or the brand (Arnett, German, \& Hunt, 2003). It is frequently shown in sports fan behavior. Individuals tend to reveal their membership in a particular social category by associating with a sport team, thereby reinforcing a desired social identity (Carlson et al., 2009). Thus, individuals may be especially attracted to a certain sporting event that is viewed as being a prestigious event because they want to form a notable identity by engaging themselves in the sporting event. For example, in addition to the fact that the FIFA World Cup is one of the most widely viewed football events in the world, individuals would consider the FIFA World Cup as one of the world's most prestigious sporting events. Moreover, individuals prefer to volunteer at a prestigious megaevent (compared with less known sporting events) because it is an unforgettable experience, which increases their social group status. They would also believe that being part of the event as volunteers is a great opportunity to increase their self-esteem, which is particularly important in fulfilling their own volunteer motivation.

Therefore, the relationship between event prestige and event identification can be considered to be a consequence of personality dimensions of the event wherein the stronger an individual identifies a brand personality with a sporting event, the greater prestige the individual accumulates on the event, which in turns leads the individual's high level of brand identification of the event. Thus, the following hypotheses were proposed:

H1: Sincerity has a positive influence on prestige.

H2: Excitement has a positive influence on prestige.

H3: Competence has a positive influence on prestige.
H4: Sophistication has a positive influence on prestige.

H5: Ruggedness has a positive influence on prestige.

H6: Prestige has a positive influence on brand identification.

\section{The Influence of Brand Identification on Intention to Return}

Volunteer retention is of key importance in most sporting events that seek a large number of individuals to help operate the events. Given that retaining volunteers helps the organizations save time and money from continuously recruiting and training new volunteers (Clary et al., 1998), it is not surprising that numerous sporting event organizations put forth remarkable efforts to enhance volunteer retention. In the consumer-brand context, McAlexander et al. (2002) noted that brand identification could reach the desirable outcomes such as high brand loyalty and positive word of mouth. Ahearne, Bhattacharya, and Gruen's (2005) study on customer-company identification indicated that the more the customers identify with a company the greater the impact on purchasing behavior. Similarly, Kuenzel and Halliday's (2008) study with a sample of car owners in the UK found brand identification plays a significant mediating role in the relationships between prestige, satisfaction, and communication and word of mouth and brand repurchase. The findings of Carlson et al.'s (2009) study in the sport context also revealed that a consumer's identification with the sport team brand had a positive impact on the number of games that fans watched and the amount of money spent on team-related retail purchases. In support of those studies, we applied the concept of consumer-brand identification in the sporting event context where volunteers' brand identification on a sporting event may encourage them to return to volunteer for the future event. This leads to the following hypothesis:

H7: Brand identification has a positive influence on volunteer intention to return.

Numerous studies explain why individuals volunteer and what factors influence their satisfaction in 
volunteering. However, little research has focused on episodic volunteers who are most of the ones volunteering at sporting events as well as their attitudes related to the unique characteristics of sporting events. Moreover, brand personality, prestige, and identification of sporting events have not drawn great attention of researchers as primary factors that influence individuals' intention to return for volunteering at future sporting events. Considering the fact that individuals build a desired social identity through the volunteer participation in a branded strong event, it is important to understand the role of branded sporting events in attracting a large number of individuals to the event. Therefore, the purpose of the study was to examine the relationship among four variables: brand personality traits, prestige of a sporting event, brand identification, and individuals' intention to return to volunteer for future sporting events. Figure 1 shows the proposed conceptual model to test the relationships. The findings of this study could contribute to a better understanding of the effects of sporting events' brand personality, prestige, and identification in individuals' decision-making process for their intention to return for future sporting events and help practitioners develop effective volunteer recruitment, training, and retention strategies.

\section{Method}

\section{Participants}

Two hundred twenty-four (224) individuals participated in a paper-based survey. More than half (57.1\%) of the participants were females while $42.9 \%$ were males. The participants' age ranged from 18 to 75 with the mean age of 31; 72.3\% were single and $27.7 \%$ were married. As for the participants' educational levels, $35.7 \%$ were classified as college graduates and professionals, $29.0 \%$ were college students, $13.4 \%$ were high school graduates, $12.5 \%$ were graduate students, $1.3 \%$ were in high school, and $8.0 \%$ listed as others. The majority of the participants $(67.9 \%)$ responded that they had not volunteered for any other sporting events before while only $32.1 \%$ had previous volunteering experiences at sporting events.

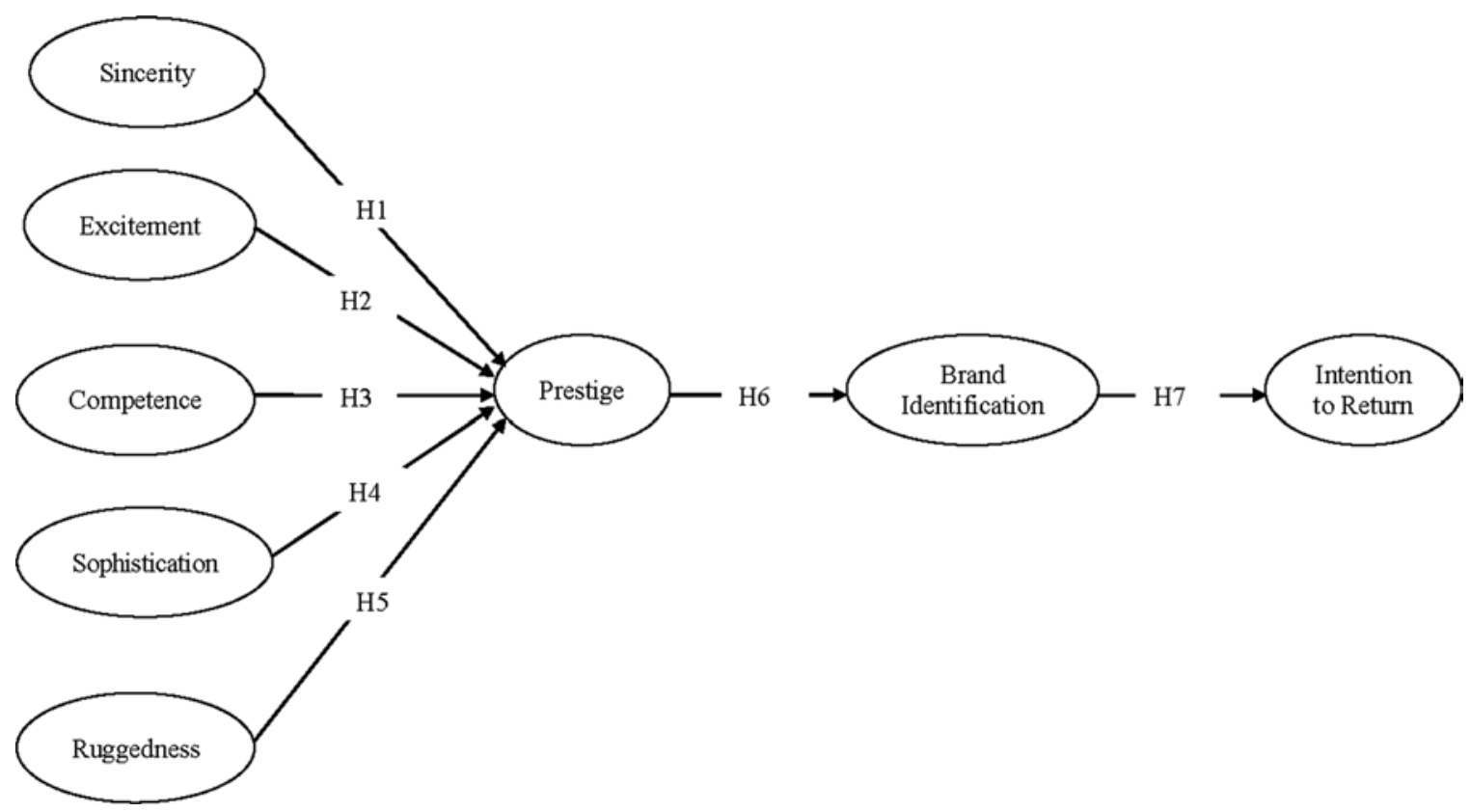

Figure 1. Conceptual model of the relationships among brand personality dimensions, prestige, brand identification, and intention to return. 


\section{Procedures}

Permission was granted by the City of Cape Town in South Africa to conduct a paper-based survey among city volunteers who had worked at the 2010 FIFA World Cup. Four hundred questionnaires were distributed to volunteer coordinators who were responsible for volunteers at the following event locations: the official FIFA Fan Park in Cape Town and at the four City of Cape Town Public Viewing Areas (Athlone, Bellville, Khayelitsha, and Mitchells Plain). The volunteer coordinators then distributed the questionnaires to their volunteers at the respective site locations over a 2-week period during the World Cup. Two hundred and twenty-four surveys were returned, which is a response rate of $56 \%$.

\section{Measures}

A paper-based form of the survey was developed, consisting of five parts: (a) brand personality, (b) prestige, (c) brand identification, (d) intention to return, and (e) demographic information. J. L. Aaker's (1997) brand personality scale (BPS) was used to measure the five dimensions of brand personality. This section contained 42 items: sincerity (11 items), excitement (11 items), competence (9 items), sophistication (6 items), and ruggedness (5 items). The scale was constructed using 42 adjectives to describe all relevant brand personality factors (e.g., down-to-earth, family oriented, and honest as the sincerity factor adjectives). Thus, the brand personality instrument instruction included that the participants were asked to imagine that the FIFA World Cup was a human being and think of the set of human characteristics associated to the FIFA World Cup. They were then asked to find out which personality traits or human characteristics come to their mind when they think of the FIFA World Cup. Responses to each of the items were measured using a 7-point Likert-type scale ranging from $\mathrm{Not}$ at all descriptive (1) to Extremely descriptive (7). Carlson et al.'s (2009) study used only the facets of each dimension, which were applicable in their sports context, and changed the names of the dimensions. However, this study used all the facets representative of each brand personality dimension and allowed the participants to respond to each facet with their thinking about the sporting event. Consumers associate personality traits with the brand not only directly, but also indirectly through product attributes, associations with the product category, name of the brand, logo, or symbol, advertising style, price, or distribution channel (Batra, Lehmann, \& Singh, 1993). Considering all the relevant attributes and associations with the FIFA World Cup, all brand personality facets of J. L. Aaker's (1997) BPS could be applicable in the participants' mind. Thus, we used the original version of Aaker's BPS rather than Carlson et al.'s modified scale.

Event prestige was measured using a three-item version of the scale proposed by Mael and Ashforth (1992). Given that brand prestige refers to the relatively high status product and/or service positioning associated with a brand (Steenkamp et al., 2003), Mael and Ashforth's (1992) three-item scale is consistent with the definition of brand prestige. Six items were adapted from Mael and Ashforth's (1992) identification scale to assess the sporting event's brand identification. The participants' intention to return for volunteering at a future event was measured using three items derived from Ajzen's (1991) theory of planned behavior questionnaire. All responses to the respective scales (7-point Likert-type) ranged from Strongly disagree (1) to Strongly agree (7). Finally, the survey included five questions assessing basic demographic information (sex, age, marital status, level of education, and previous volunteering experiences at sporting events) for the purpose of developing a respondent profile. The final instrument thus included 59 items. In South Africa, because the dominant language in government and the media is English, the questionnaire was provided in English.

\section{Data Analyses}

Using the statistics program LISREL 8.72, confirmatory factor analysis (CFA) was performed to examine how well variables define their respective construct (Guarino, 2004), which helps to establish construct validity. To examine the reliability of the data, internal consistency estimates for the items selected to represent the variables were computed using Cronbach's alpha (Brown, 2002). For testing convergent validity, each item loaded on the construct was examined in order to assess whether the scale appeared to be measuring the same construct 
(Anderson \& Gerbing, 1988). To evaluate the discriminant validity of the constructs, the average variance extracted (AVE) test (Fornell \& Larcker, 1981) was performed. Structural equation modeling (SEM) was then conducted based on the proposed hypotheses (see Fig. 1).

\section{Results}

\section{Measurement Model}

The measurement model included 54 items comprising the eight constructs: sincerity, excitement, competence, sophistication, ruggedness, brand identification, prestige, and volunteer intention. As a rule of thumb, Hair, Anderson, Tatham, and Black (1998) classify loadings above 0.6 "high" and those below 0.4 "low", and we used 0.4 as a cutoff point for factor loadings. Thus, after removing factor loadings below 0.4 , a total of 36 items remained in the final measurement model. The removed items were as follows: "small-town,” “original,” “cheerful,” “sentimental," and "friendly" from the sincerity factor; "exciting," "spirited," "cool," "unique," and "independent” from the excitement factor; "reliable," "secure," and "successful" from the competence factor; "upper class" and "feminine" from the sophistication factor; and "outdoorsy" from the ruggedness factor. The final items selected for inclusion in the current study demonstrated strong face validity. Although previous studies (e.g., Braunstein \& Ross, 2010; Carlson et al., 2009) used J. L. Aaker's BPS with different construct labels and revised the BPS by adding new dimensions to measure brand personality in sport, many of those studies basically utilized most of the BPS descriptor items, and the new dimensions were more applicable in the context of professional sport teams, which is incompatible with the current study's context of large-scale international sport events. Thus, this study kept and used the original five dimensions of J. L. Aaker's (1997) BPS.

Results from CFA revealed that the chi-square test was significant $\left[X^{2}(566)=1078.10, p<0.01\right]$, which would indicate an unacceptable fit. However, given that the chi-square test statistic is very sensitive to multivariate normality and produces unstable results with the violation of this basic assumption, other fit statistics were investigated to assess the overall fit of the model to the data (Gerbing \&
Anderson, 1993). The alternative fit indices indicated a reasonable fit of the data. The CFI (0.97), the NNFI (0.97), and the IFI (0.97) were higher than 0.90 , which is desirable for an acceptable model fit (Kelloway, 1998; Kline, 1998). The RMR value (0.063) and the RMSEA (0.064) were acceptable with the recommended criteria of 0.08 for a reasonable fit (Browne \& Cudeck, 1993; Steiger, 1998). Table 1 shows that the items for each construct significantly loaded on their corresponding construct (the minimum $t$ value was 7.40 ) with their factor loadings greater than 0.4. Thus, the CFA results indicated that the measurement model achieved an adequate fit for the proposed factor dimensions, providing evidence of factorial validity and convergent validity of the study's measurement (Bagozzi \& Yi, 1988). To establish discriminant validity the study examined AVE by the different constructs. The AVE value demonstrates the degree to which items differentiate among constructs or measure distinct concepts (Fornell \& Larcker, 1981). Guidelines suggest that the AVE value should exceed 0.50 for a construct. The AVE values were greater than 0.50 for most of the constructs (see Table 1). However, ruggedness had AVE value (0.46) less than 0.50 in which case the study utilized a test by Fornell and Larcker (1981). The test shows that ruggedness demonstrates discriminant validity because its AVE (0.46) is greater than the square of its correlations with sincerity $\left(0.24^{2}=0.06\right)$, excitement $\left(0.47^{2}=0.22\right)$, competence $\left(0.51^{2}=0.26\right)$, sophistication $\left(0.49^{2}=0.24\right)$, prestige $\left(0.36^{2}=0.13\right)$, brand identification $\left(0.34^{2}=0.12\right)$, and volunteer intention $\left(0.05^{2}=0.00\right)$. The reliabilities ranged from 0.74 to 0.89 , meeting the minimum level $(0.70)$ recommended by Nunnally and Bernstein (1994). The internal consistency estimates of the eight factors are shown in Table 1. The mean scores of the five brand personality dimensions were ranked as follows: competence $(M=5.75, S D=1.10)$, excitement $(M=5.38, \quad S D=1.10)$, sophistication $(M=5.34$, $S D=1.29)$, sincerity $(M=5.10, S D=1.27)$, and ruggedness $(M=4.98, S D=1.28)$. Mean scores of prestige, brand identification, and volunteer intention were $(M=5.95, S D=1.16),(M=5.50$, $S D=1.45)$, and $(M=6.36, S D=.99)$, respectively. Table 2 presents the descriptive statistics including means, standard deviations, and correlations among the eight constructs. 
Table 1

Items, Factor Reliabilities, Individual Item Loadings, and $t$ Values of the Measurement Model

\begin{tabular}{|c|c|c|}
\hline Items & $\begin{array}{l}\text { Standardized } \\
\text { Factor Loading }\end{array}$ & $t$ Value \\
\hline \multicolumn{3}{|l|}{ Sincerity $(\alpha=0.88, \mathrm{AVE}=0.54)$} \\
\hline Down-to-earth & 0.70 & 11.56 \\
\hline Family oriented & 0.66 & 10.82 \\
\hline Honest & 0.78 & 13.49 \\
\hline Sincere & 0.83 & 14.74 \\
\hline Real & 0.74 & 12.60 \\
\hline Wholesome & 0.78 & 13.52 \\
\hline \multicolumn{3}{|l|}{ Excitement $(\alpha=0.84, \mathrm{AVE}=0.50)$} \\
\hline Daring & 0.68 & 11.16 \\
\hline Trendy & 0.71 & 11.69 \\
\hline Young & 0.49 & 7.40 \\
\hline Imaginative & 0.79 & 13.75 \\
\hline Up-to-date & 0.72 & 12.10 \\
\hline Contemporary & 0.76 & 12.84 \\
\hline \multicolumn{3}{|l|}{ Competence $(\alpha=0.89, \mathrm{AVE}=0.59)$} \\
\hline Hard working & 0.82 & 14.72 \\
\hline Intelligent & 0.83 & 14.91 \\
\hline Technical & 0.71 & 11.88 \\
\hline Corporate & 0.68 & 11.17 \\
\hline Leader & 0.82 & 14.58 \\
\hline Confident & 0.71 & 11.91 \\
\hline \multicolumn{3}{|l|}{ Sophistication $(\alpha=0.88, \mathrm{AVE}=0.67)$} \\
\hline Glamorous & 0.81 & 14.17 \\
\hline Good looking & 0.84 & 15.05 \\
\hline Charming & 0.79 & 13.68 \\
\hline Smooth & 0.76 & 12.90 \\
\hline \multicolumn{3}{|l|}{ Ruggedness $(\alpha=0.74, \mathrm{AVE}=0.46)$} \\
\hline Masculine & 0.72 & 11.12 \\
\hline Western & 0.54 & 7.80 \\
\hline Tough & 0.76 & 11.87 \\
\hline Rugged & 0.57 & 8.37 \\
\hline \multicolumn{3}{|l|}{ Prestige $(\alpha=0.79, \mathrm{AVE}=0.59)$} \\
\hline The people around me have a positive image of the FIFA World Cup & 0.84 & 14.75 \\
\hline In general, the FIFA World Cup is highly respected & 0.69 & 11.29 \\
\hline The FIFA World Cup has a good reputation with the general public & 0.71 & 11.73 \\
\hline \multicolumn{3}{|l|}{ Brand Identification $(\alpha=0.86$, AVE $=0.66)$} \\
\hline When someone praises the FIFA World Cup, it feels like a personal compliment & 0.71 & 11.64 \\
\hline When I talk about the FIFA World Cup, I usually say "we" rather than "they" & 0.76 & 12.92 \\
\hline If a story in the media criticized the FIFA World Cup, I would feel embarrassed & 0.80 & 13.79 \\
\hline When someone criticizes the FIFA World Cup, it feels like a personal insult & 0.88 & 16.06 \\
\hline \multicolumn{3}{|l|}{ Volunteer intention $(\alpha=0.81, \mathrm{AVE}=0.59)$} \\
\hline $\begin{array}{l}\text { I will volunteer at the next FIFA World Cup (if it is held in South Africa again } \\
\text { in } 4 \text { years) }\end{array}$ & 0.95 & 16.79 \\
\hline $\begin{array}{l}\text { I intend to volunteer at the next FIFA World Cup (if it is held in South Africa } \\
\text { again in } 4 \text { years) }\end{array}$ & 0.54 & 8.37 \\
\hline $\begin{array}{l}\text { I am determined to do some volunteer work at the next FIFA World Cup } \\
\text { (if it is held in South Africa again in } 4 \text { years) }\end{array}$ & 0.84 & 14.27 \\
\hline
\end{tabular}

S-B $\chi^{2}(566)=1078.10, p=0.00$. Goodness of fit measures: CFI, 0.97; NNFI, 0.97; IFI, 0.98; RMR, 0.063; RMSEA, 0.064. 
Table 2

Descriptive Statistics and Correlations for all Variables

\begin{tabular}{lccccccccc}
\hline Variable & $M$ & $S D$ & 1 & 2 & 3 & 4 & 5 & 6 & 7 \\
\hline 1. Sincerity & 5.10 & 1.27 & & & & & & & \\
2. Excitement & 5.38 & 1.10 & $0.63^{* *}$ & & & & & & \\
3. Competence & 5.75 & 1.10 & $0.59^{* *}$ & $0.77^{* *}$ & & & & & \\
4. Sophistication & 5.34 & 1.29 & $0.54^{* *}$ & $0.65^{* *}$ & $0.67^{* *}$ & & & & \\
5. Ruggedness & 4.98 & 1.28 & $0.24^{* *}$ & $0.47^{* *}$ & $0.51^{* *}$ & $0.49^{* *}$ & & & \\
6. Prestige & 5.95 & 1.16 & $0.68^{* *}$ & $0.56^{* *}$ & $0.62^{* *}$ & $0.57^{* *}$ & $0.36^{* *}$ & & \\
7. Brand identification & 5.50 & 1.45 & $0.54^{* *}$ & $0.48^{* *}$ & $0.48^{* *}$ & $0.53^{* *}$ & $0.34^{* *}$ & $0.62^{* *}$ & \\
8. Volunteer intention & 6.36 & 0.99 & $0.44^{* *}$ & $0.33^{* *}$ & $0.31^{* *}$ & $0.29^{* *}$ & 0.05 & $0.41^{* *}$ & $0.21^{* *}$ \\
\hline
\end{tabular}

$* * p<0.01$ (two-tailed).

\section{Structural Model (Testing Hypotheses)}

Results of the proposed model using SEM revealed that prestige plays an important role in mediating the three dimensions of brand personality and brand identification, which further influences intention to return. According to the SEM results, although the chi-square value $\left[\chi^{2}(577)=1124.05\right.$, $p<0.01$ ] was significant, other fit indices appeared satisfactory (CFI $=0.97, \mathrm{NNFI}=0.97, \mathrm{IFI}=0.97$, $\mathrm{RMR}=0.080$, and RMSEA $=0.065$ ). This indicates that the structural model had an acceptable fit with the data. First, three constructs of brand personality had a significant direct, positive influence on prestige: sincerity $(\mathrm{H} 1$; standardized coefficient $=0.58$, $p<0.001$ ), competence (H3; standardized coefficient $=0.41, p<0.05$ ), and sophistication (H4; standardized coefficient $=0.23, p<0.05$ ). This lends substantial support to H1, H3, and H4. H6 was also supported in that prestige had a positive influence on brand identification (standardized coefficient $=0.80, p<0.001$ ). The model suggests that volunteers' higher levels of the brand personality facets that reflect on sincerity, competence, and sophistication of the sporting event are likely to increase their levels of prestige on the event, thereby leading to higher levels of their brand identification of the event.

H7, which proposed the positive impact of brand identification on volunteers' intention to return, was accepted (standardized coefficient $=0.66$, $p<0.001$ ). The results therefore give support to the postulation that brand identification has a significant positive impact on individuals' intention to return to volunteer for future events. Table 3 presents a summary of the structural equation model results including standardized coefficients for the structural relations. Figure 2 shows the final structural model with the significant relationships.

\section{Discussion}

This study attempted to examine the relationship among four variables: brand personality traits, prestige of a sporting event, brand identification, and individuals' intention to return to volunteer for future sporting events. The integrated model of the links between brand personality, prestige, brand identification, and intention to return for volunteering constitutes the major conceptual contribution of this study. The findings partly supported the notion that prestige acts as a mediator variable between brand personality and brand identification that predicts volunteers' intention to return. The study contributes to the existing literature by extending the analysis of brand personality of a sporting event and by providing a more sophisticated explanation of how branded sporting events influence individuals' intentions to return for volunteering.

\section{Mediating Role of Prestige in the Relationship Between Brand Personality and Brand Identification}

Results reveal that three of the five brand personality traits-sincerity, competence, and sophistication-are likely to reinforce their perception of event prestige. The findings are consistent with those of Carlson et al.'s (2009) study. Carlson et al.'s study found that the two brand personality dimensions of wholesomeness (i.e., sincerity) and successfulness (i.e., competence) were mediated through prestige 
Table 3

Structural Equation Model Results

\begin{tabular}{llcc}
\hline Hypotheses & \multicolumn{1}{c}{ Structural Relationship } & $\begin{array}{c}\text { Standardized } \\
\text { Coefficient }\end{array}$ & $t$-value \\
\hline H1 & Sincerity $\rightarrow$ Prestige & 0.58 & $5.94^{* * *}$ \\
H2 & Excitement $\rightarrow$ Prestige & -0.32 & -1.92 \\
H3 & Competence $\rightarrow$ Prestige & 0.41 & $2.46^{*}$ \\
H4 & Sophistication $\rightarrow$ Prestige & 0.23 & $2.35^{*}$ \\
H5 & Ruggedness $\rightarrow$ Prestige & 0.10 & 1.14 \\
H6 & Prestige $\rightarrow$ Brand Identification & 0.80 & $8.84^{* * *}$ \\
H7 & Brand Identification $\rightarrow$ Intention to Return & 0.66 & $3.78^{* * *}$ \\
\hline
\end{tabular}

S-B $\chi^{2}(577)=1124.05, p=0.00$. Goodness-of-fit measures: CFI, 0.97; NNFI, 0.97; IFI, 0.97; RMR, 0.080; RMSEA, 0.065.

${ }^{*} p<0.05 ; * * * p<0.001$.

to predict the consumer's identification with a sport team. As for the significant influence of sincerity on prestige, volunteers perceive the FIFA World Cup as being more credible and sincere in that the sporting event provides wholesome entertainment for people. The history of the FIFA World Cup, which has grown into one of the biggest single-sport events in the world, also has a sincere and trustworthy history to strengthen the good reputation and image constantly. Such perceptions of the sporting event relate to sporting event prestige, indicating that volunteers attribute an honest and wholesome image with a prestigious sport event. From a different perspective, they are likely to express their similar self-concept as honest and wholesome through volunteering at the event. Regarding the significant influence of competence on prestige, individuals seem to match the image of the FIFA World Cup as a premier sporting event in the world, which brings the world's strongest national football teams, with their own image. According to Afzal, Khan, Rehman, Ali, and Wajahat (2010), the properties of a brand have an important function in

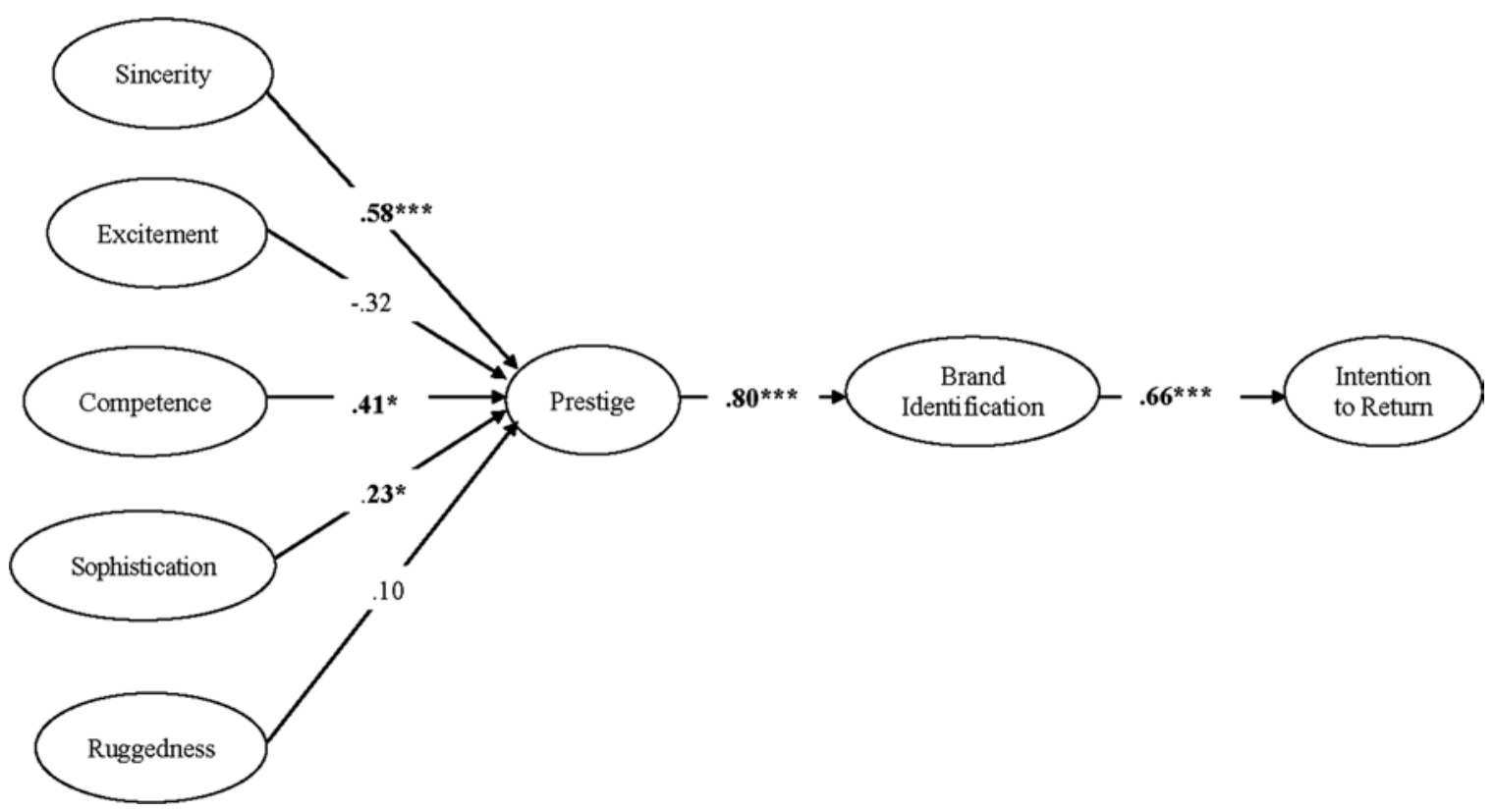

Figure 2. Final model of the relationships among brand personality dimensions, prestige, brand identification, and intention to return. ${ }^{*} p<0.05 ; * * * p<0.001$. 
forming trust, which improves consumers’ perceived brand prestige in market. Moreover, to evaluate brand capabilities buyers tend to see whether other buyers have the same opinion about brand as worthy of praise (Afzal et al., 2010). Thus, it is speculated that as one of the world's leading sport events, the FIFA World Cup's secured resources by various stakeholders (i.e., competence) such as government support, volunteer contribution, and engaged sponsorship may contribute to individuals' perceived event prestige as it is consistent with their desired self-image. Sophistication was also found to have a significant influence on prestige. This suggests that individuals may want to incorporate the FIFA World Cup's trait, such as artistic football venues, expensive game tickets, ensured smooth operations, and charming tourism attractions of a host city, into the prestigious sporting event, which is congruent with their self-concept.

However, the influence of excitement on prestige was not significant. The FIFA World Cup has been viewed as the most watched sporting event in the world with a long and glorious history. Thus, the excitement dimension, including the young and contemporary items, might be less relevant for the volunteers' perceived prestige of such a historic event as the FIFA World Cup. With regard to the nonsignificant influence of ruggedness on prestige, the quality of toughness the respondents have may probably be irrelevant with the sporting event's specific trait or may not be their desirable self-congruity. In addition, more than half of the participants in this study were female volunteers (57.1\%). As masculine and tough are contained as the items of the ruggedness dimension, the tough and rugged brand personality trait of the sporting event might not contribute to the perceived brand prestige among female volunteers.

Those findings on the significant influences of the three brand personality traits on prestige support the self-congruity theory. Particularly, brand personality traits can be further contextually detailed beyond general personality attributes to match one's selfconcept. According to Carlson et al. (2009), higher levels of the brand personality facets enhance the prestige value of a brand in which individuals perceive as more similar to their ideal self-image. Volunteers may prefer a certain sporting event for their volunteering activity because the sporting event shaped by its sincerity, competence, and sophistication is perceived as a prestigious sporting event. The volunteers might further desire to gain a sense of social status (enhancing their self-concept) associated with volunteering at a prestigious event (Bussell \& Forbes, 2002).

The findings on the significant influence of prestige on brand identification support the social identity theory (Tajfel \& Turner, 1979), proposing that individuals tend to use a variety of factors to classify themselves as belonging to a specific group. Arnett et al.'s (2003) study, which examined nonprofitdonor relationships in a university setting, found that perceived organizational prestige is positively associated with organizational identification. They viewed such relationships as a sense of oneness with or belongingness to an organization. The prestige of an organization often serves as an indicator of organizational success (Bhattacharya, Rao, \& Glynn, 1995). Accordingly, if the brand image is perceived as prestigious by consumers, this may boost their pride in identifying with a prestigious brand (Ahearne et al., 2005; Dutton, Dukerich, \& Harquail, 1994). In line with previous studies, our findings show that individuals may be able to identify and choose a prestigious sporting event because they might consider the prestigious event as a successful, well-known event. Furthermore, volunteers believe that the distinguished characteristics of a sporting event are consistent with their actual self-concept (e.g., respect and status), thereby identifying the sporting event over other events for their volunteer participation as a mechanism to enhance their self-consistency.

\section{The Influence of Brand Identification on Intention to Return}

The enhanced brand identification seems to affect the individuals' intention to return to volunteer for future events by optimizing their feeling of being at the prestigious events. According to Bhattacharya and Sen (2003), identifying prestigious companies can be considered as a key factor for consumers to maintain their self-enhancement and satisfy their selfesteem so that the degree of consumer-company identification positively influences consumer purchase intentions. Similarly, in the sporting event context, if individuals perceive a certain sporting 
event as prestigious and eminent, their pride seems to be maximized with volunteering at the prestigious sporting event. In addition, Bang et al. (2009) noted that personal growth (i.e., increasing self-worth and self-esteem) is one of the important motivations of volunteering at sporting events. Volunteers' original motivation to enhance self-esteem through volunteering might add to such maximized feelings about themselves. Volunteering at the prestigious sporting event would then be ideal behavior to them. Consequently, event prestige reinforced by brand personality seems to eventually play an essential role in improving volunteers' identification with the sporting event, resulting in higher levels of intention to return for volunteering.

\section{Practical Implications}

This study offers a first general implication for event volunteer management-discovering the mechanism from sporting event brand personality to volunteer intention to return, which reflects significant relationships for individuals with a huge potential for giving positive affective and behavioral responses by volunteering at the sporting event. From a managerial perspective, the study provides a better understanding of how brand personality may be used to create individuals' perception of event prestige, which is associated with the sporting event identification and differentiation. Numerous researchers recognize a major managerial advantage of the brand personality concept in that brand personality can influence the relationship that a consumer has with a brand and explain that consumer's behavior (Louis \& Lombart, 2010). Therefore, event managers and/or volunteer managers should pay more attention to the influence of brand personality on the prestige associated with their sporting event and strive to enhance individuals' level of brand identification. For example, event mangers might focus on the visibility and reputation of a sporting event via external communication, which could have a positive influence on the prestige of the sporting event. Such efforts may attract more people to have a great interest in volunteering at a branded sporting event given that they would feel proud of being part of that sporting event. Graeff (1996) suggests that the congruence between brand image and self-image is likely to influence brand evaluation relating to promotion message. Thus, the volunteer recruitment message that reminds individuals of their own self-image would help the individuals perceive the sporting event more positively, thereby increasing their intention to volunteer for the event. Moreover, results showed that the perceived event prestige influenced by its personality traits has a positive impact on event identification. This highlights the importance of effective volunteer training, communication, and reward system, because volunteers might want to confirm a sporting event that provides a successful operational system, which enhances a favorable, prestigious image of the event. To do this most effectively event managers may have to establish an effective volunteer recruitment and management plan.

\section{Limitations and Future Research}

The present study has certain limitations that need to be taken into account, which can be seen as fruitful avenues for future research. First, the study measured the brand personality of the sporting event using J. L. Aaker's (1997) brand personality scale. Although Aaker's brand personality inventory has been acknowledged as a robust and reliable scale in numerous consumer behavior studies, it may not be completely adaptable to the sporting event context due to the unique characteristics associated with sport and sport products (Braunstein \& Ross, 2010). Therefore, future research needs to develop a specific scale that measures brand personality clearly adapted to the sport context. Second, numerous studies found a high correlation between intention and behavior. Concerning the measurement of intention, Ajzen (1985) noted that two conditions must be satisfied for intentions to be fully converted to the behavior in question: (1) the behavior must be under a subject's volitional control, and (2) intention must be measured right before the behavior, given that intentions possibly change as time goes by due to newly obtained information or changes in belief. However, we asked the volunteers to imagine the event is held in the same place again in 4 years and measured their intention to return for the next event. The given assumption was somewhat unrealistic, and the volunteers' intention to return in 4 years is probably unstable even if it was a real story. Their high levels of intention measured in this study may 
be insufficient to predict their behavior. Third, this study tested the relationships between brand personality, brand identification, prestige, and volunteer intention. Yet additional theoretical relationships, including potential factors such as subjective norm and moral obligation, could be examined within the study's proposed framework, providing a better picture of the structural relationships in a future study. Finally, this study measured only a few sociodemographic variables (sex, age, marital status, level of education, and previous volunteering experiences at sporting events), which included limited information about the sample characteristics. Thus, future research that measures more sociodemographic variables (e.g., ethnic background and place of residence variables) is necessary to provide a more detailed profile of sample respondents.

\section{References}

Aaker, D. A. (1991). Managing brand equity: Capitalizing on the value of a brand name. New York: The Free Press.

Aaker, J. L. (1996). Exploring brand equity: Building strong brands. New York: The Free Press.

Aaker, J. L. (1997). Dimensions of brand personality. Journal of Marketing Research, 34(3), 347-356.

Aaker, J. L., Benet-Martinez, V., \& Garolera, J. (2001). Consumption symbols as carriers of culture: A study of Japanese and Spanish brand personality constructs. Journal of Personality and Social Psychology, 81(3), 492-508.

Afzal, H., Khan, M. A., Rehman, K., Ali, I., \& Wajahat, S. (2010). Consumer's trust in the brand: Can it be built through brand reputation, brand competence and brand predictability. International Business Research, 3(1), 43-51.

Ahearne, M., Bhattacharya, C. B., \& Gruen, T. (2005). Antecedents and consequences of customer-company identification: expanding the role of relationship marketing. Journal of Applied Psychology, 90(3), 574-585.

Ajzen, I. (1985). From intentions to actions: A theory of planned behavior. In J. Kuhl \& J. Beckmann (Eds.), Springer series in social psychology (pp. 11-39). Berlin, Germany: Springer.

Ajzen, I. (1991). The theory of planned behavior. Organizational Behavior and Human Decision Processes, 50(2), 179-211.

American Marketing Association. (2008). Dictionary of marketing terms. Retrieved from http://www.marketingpower.com/_layouts/Dictionary.aspx

Anderson, J. C., \& Gerbing, D. W. (1988). Structural equation modeling in practice: A review and recommended twostep approach. Psychological Bulletin, 103(3), 411-423.

Arnett, D., German, B., \& Hunt, S. D. (2003). The identity salience model of relationship marketing success:
The case of nonprofit marketing. Journal of Marketing, 67(2), 89-105.

Bagozzi, R. P., \& Dholakia, U. M. (2006). Open source software user communities: A study of participation in Linux user groups. Management Science, 52(7), 1099-1115.

Bagozzi, R. P., \& Yi, Y. (1988). On the evaluation of structural equation models. Journal of the Academy of Marketing Science, 16(1), 74-94.

Bang, H., Alexandris, K., \& Ross, S. (2009). Validation of the revised volunteer motivations scale for international sporting events (VMS-ISE) at the Athens 2004 Olympic Games. Event Management, 12(3/4), 119-131.

Baron, R. M., \& Kenny, D. A. (1986). The moderatormediator variable distinction in social psychological research: Conceptual, strategic, and statistical considerations. Journal of Personality \& Social Psychology, 51(6), 1173-1182.

Batra, R., Lehmann, D. R., \& Singh, D. (1993). The brand personality component of band goodwill: Some antecedents and consequences. In D. A. Aaker \& A. Biel (Eds.), Brand equity and advertising (pp. 83-96). Hillsdale, NJ: Lawrence Erlbaum Associates.

Baum, T., \& Lockstone, L. (2007). Volunteers and mega sporting events: Developing a research framework. International Journal of Event Management Research, 3(1), 29-41.

Belk, R. W. (1991). The ineluctable mysteries of possessions. Journal of Social Behavior and Personality, 6(6), 17-55.

Bhattacharya, C. B., Rao, H., \& Glynn, M. (1995). Understanding the bond of identification: An investigation of its correlates among art museum members. Journal of Marketing, 59(4), 46-57.

Bhattacharya, C. B., \& Sen, S. (2003). Consumer-company identification: A framework for understanding consumers' relationships with companies. Journal of Marketing, 67(2), 76-88.

Braunstein, J. R., \& Ross, S. D. (2010). Brand personality in sport: Dimension analysis and general scale development. Sport Marketing Quarterly, 19(1), 8-16.

Brown, J. D. (2002). Statistics corner. Questions and answers about language testing statistics: The Cronbach alpha reliability estimate. Shiken: JALT Testing \& Evaluation SIG Newsletter, 6(1), 14-16. Retrieved from http://www. jalt.org/test/bro_13.htm

Browne, M. W., \& Cudeck, R. (1993). Alternative ways of assessing model fit. In K. A. Bollen \& J. S. Long (Eds.), Testing structural equation models (pp. 136-162). Beverly Hills, CA: Sage.

Bussell, H., \& Forbes, D. (2002). Understanding the volunteer market: The what, where, who and why of volunteering. International Journal of Nonprofit and Voluntary Sector Marketing, 7(3), 244-257.

Carlson, B. D., Donavan, D. T., \& Cumiskey, K. J. (2009). Consumer-brand relationships in sport: Brand personality and identification. International Journal of Retail \& Distribution Management, 37(4), 370-384.

Chang, K. S., Park, J. Y., \& Choi, I. H. (2001). The influence of self-congruity between brand personality and 
self-image on attitude toward brand. Korean Journal of Marketing, 3(2), 92-114.

Chang, P. L., \& Chieng, M. H. (2006). Building consumerbrand relationship: A cross-cultural experiential view. Psychology \& Marketing, 23(11), 927-959.

Chaplin, L. N., \& John, D. R. (2005). The development of self-brand connections in children and adolescents. Journal of Consumer Research, 32(1), 119-129.

Clary, E. G., Snyder, M., Ridge, R. D., Copeland, J., Stukas, A. A., Haugen, J., \& Miene, P. (1998). Understanding and assessing the motivations of volunteers: A functional approach. Journal of Personality and Social Psychology, 74(6), 1516-1530.

Deeter-Schmelz, D. R., Moore, J. N., \& Goeble, D. J. (2000). Prestige clothing shopping by consumers: A confirmatory assessment and refinement of the Precon scale with managerial implications. Journal of Marketing Theory and Practice, 8(2), 43-58.

Dubois, B., \& Czellar, S. (2002). Prestige brands or luxury brand? An exploratory inquiry on consumer perceptions. In Proceedings of the 31st EMAC Conference, University of Minho, Portugal, May 28-31.

Dutton, J. E., Dukerich, J. M., \& Harquail, C. V. (1994). Organizational images and member identification. Administrative Science Quarterly, 39(2), 239-263.

Ekinci, Y., \& Hosany, S. (2006). Destination personality: An application of brand personality to tourism destinations. Journal of Travel Research, 45(2), 127-139.

Escalas, J. E., \& Bettman, J. R. (2005). Self-construal, reference groups, and brand meaning. Journal of Consumer Research, 32(3), 378-389.

Farrell, J. M., Johnston, M. E., \& Twynam, G. D. (1998). Volunteer motivation, satisfaction, and management at an elite sporting competition. Journal of Sport Management, 12(4), 288-300.

Fornell, C., \& Larcker, D. F. (1981). Evaluating structural equations models with unobservable variables and measurement error: Algebra and statistics. Journal of Marketing Research, 18(1), 39-50.

Gerbing, D. W., \& Anderson, J. C. (1993). Monte Carlo evaluations of goodness-of-fit indices for structural equation models. In K. A. Bollen \& J. S. Long (Eds.), Testing structural equation models (pp. 40-65). Newbury Park, CA: Sage.

Graeff, T. R. (1996). Image congruence effects on product evaluations: The role of self-monitoring and public/private consumption. Psychology and Marketing, 13(5), 481-499.

Grubb, E. L., \& Grathwohl, H. L. (1967). Consumer selfconcept, symbolism and market behavior: A theoretical approach. Journal of Marketing, 31(4-1), 22-27.

Guarino, A. J. (2004). A comparison of first and second generation multivariate analyses: Canonical correlation analysis and structural equation modeling. Florida Journal of Educational Research, 42(1), 22-40.

Gwinner, K. (1997). A model of image creation and image transfer in event sponsorship. International Marketing Review, 14(3), 145-158.
Hair, Jr., J. F., Anderson, R. E., Tatham, R. L., \& Black, W. C. (1998). Multivariate data analysis (5th ed.). Upper Saddle River, NJ: Prentice Hall.

Kelloway, E. K. (1998). Using LISREL for structural equation modeling: A researcher's guide. Thousand Oaks, CA: Sage.

Kline, R. B. (1998). Principles and practice of structural equation modeling. New York: Guilford.

Kressman, F., Sirgy, M. J., Herrman, A., Huber, F., Huber, S., \& Lee, D. J. (2006). Direct and indirect effects of selfimage congruence on brand loyalty. Journal of Business Research, 59(6), 955-964.

Kuenzel, S., \& Halliday, S. (2008). Investigating antecedents and consequences of brand identification. Journal of Product and Brand Management, 17(5), 293-304.

Louis, D., \& Lombart, C. (2010). Impact of brand personality on three major relational consequences (trust, attachment, and commitment to the brand). Journal of Product \& Brand Management, 19(2), 114-130.

Mael, F., \& Ashforth, B. (1992). Alumni and their alma maters: A partial test of the reformulated model of organizational identification. Journal of Organizational Behavior, 13(2), 103-123.

McAlexander, J. H., Schouten, J. W., \& Koenig, H. F. (2002). Building brand community model of organizational identification. Journal of Marketing, 66(1), 38-54.

Nunnally, J. C., \& Bernstein, I. H. (1994). Psychometric theory (3rd ed.). New York: McGraw-Hill.

Rosenberg, M. (1979). Conceiving the self. New York: Basic Books.

Schwartz, P. J. (2007, January 31). The world's most valuable sporting event brands. Retrieved from http://www. forbes.com/2007/01/30/sports-brands-superbowl-biz-cz ps_0131mvse.html

Sirgy, M. J. (1982). Self-concept in consumer behavior: A critical review. Journal of Consumer Research, 9(2), 287-300.

Sirgy, M. J. (1986). Self-congruity: Toward a theory of personality and cybernetics. New York: Praeger.

Sirgy, M. J., Grewal, D., \& Mangleburg, T. F. (2000). Retail environment, self-congruity, and retail patronage: An integrative model and research agenda. Journal of Business Research, 49(2), 127-138.

Steenkamp, J. B. E. M., Batra, R., \& Alden, D. L. (2003). How perceived brand globalness creates brand value. Journal of International Business Studies, 34(1), 53-65.

Steiger, J. H. (1998). A note on multiple sample extensions of the RMSEA fit index. Structural Equation Modeling, 5(4), 411-419.

Tajfel, H., \& Turner, J. C. (1979). An integrative theory of intergroup conflict. In W. G. Austin \& S. Worchel (Eds.), The social psychology of intergroup relations (pp. 33-47). Monterey, CA: Brooks-Cole.

Vancouver 2010. (2010). Work and volunteer. Retrieved from http://www.vancouver2010.com/more-2010-information/ work-and-volunteer/volunteer-opportunities/ 